\title{
Oesophageal reflux and gastric secretion
}

\author{
A. S. WARD
}

From the Queen Elizabeth Hospital, Birmingham

SUMMARY In the study to be described confirmation of the findings of Giles, Clark, and Buchan (1968) that the presence of acid in the lower oesophagus may stimulate gastric secretion has been sought. Also the influence of hiatal repair on the response to acid has been examined.

The presence of acid in the lower oesophagus stimulates gastric secretion in man.

The response to acid perfusion is greater in symptomatic hiatus hernia patients than in controls.

Basal and perfusion outputs are lower in hiatus hernia patients with oesophagitis than in those without inflammatory change.

Hiatal repair diminishes the gastric response in both groups; this effect is particularly marked in patients with oesophagitis.

Little is known of the influence of the oesophagus on gastric secretion. Giles, Clark, and Buchan (1968), however, have recently reported that the presence of acid in the lower oesophagus may stimulate gastric secretion. This observation has particular relevance to hiatus hernia patients, many of whom experience acid reflux into the oesophagus. A vicious circle may occur in such patients in which acid reflux produces increased gastric secretion, which in turn leads to further reflux. Gastric stimulation by acid in the oesophagus has been demonstrated so far only in patients with oesophagitis and may be an important factor in maintaining or even initiating the inflammatory response. Confirmation of the findings of Giles et al (1968) has been sought in the present study, and in addition the influence of hiatal repair on the response has been examined.

\section{Materials and Methods}

The lower oesophagus was perfused with acid while basal gastric secretion was measured.

Received for publication 28 April 1970.
After the patient had fasted overnight a modified Salem sump tube was passed via the nose into the body of the stomach. The tube was constructed with a fine perfusion limb opening onto the surface of the collecting tube 14 in. proximal to the tip: this distance was chosen so that when correctly placed the perfusion zone lay 7 in. above the cardia and the collection zone a similar distance below this point (Fig. 1).

Gastric sampling was by continuous suction and 10-minute collections were made throughout. The basal secretory rate was measured for one hour. Then $20 \mathrm{ml} \mathrm{N} / 10$ hydrochloric acid, labelled with $1 \%$ polyethylene glycol at $37^{\circ} \mathrm{C}$, was instilled down the fine tube into the oesophagus over a 15-minute period. Gastric collection was continued for at least 50 minutes after beginning the infusion. Estimation of the concentration of polyethylene glycol (PEG) in recovered gastric samples enabled the endogenous secretion to be distinguished from acid introduced at the perfusion site.

The response to oesophageal perfusion has been assessed by comparing mean acid output during the basal hour with the mean output in 


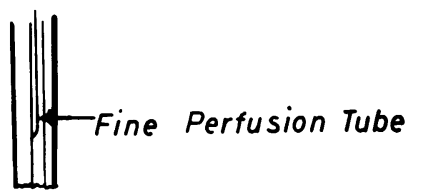

pathology was evident either on radiological examination or at operation. Oesophagoscopy was carried out at the time of testing and the presence or absence of inflammatory change noted. The degree of oesophagitis was classed as A (reddening and oedema of the mucosa), B (a red mucosa bleeding easily on touch), C (ulceration, stricture, or membrane formation). There were three grade A patients, two grade B, and eight grade $C$ patients. In the remaining seven no evidence of oesophagitis was found at endoscopy.

Tests were repeated three to four months after operation in 12 patients. A standard plastic repair of the hiatus was carried out in all cases (Collis, 1961 and 1968).

The controls comprised nine males and five females (mean age 55 years) selected from hospital staff and volunteer patients recovering from minor operations; all were free of abdominal and thoracic symptoms. In nine subjects $N / 10$ hydrochloric acid was instilled into the oesophagus in the same way as in the hiatus hernia patients. The remaining five controls received $20 \mathrm{ml}$ physiological $(0.9 \%)$ saline, labelled with $1 \%$ PEG and at $37^{\circ} \mathrm{C}$, instead of hydrochloric acid.

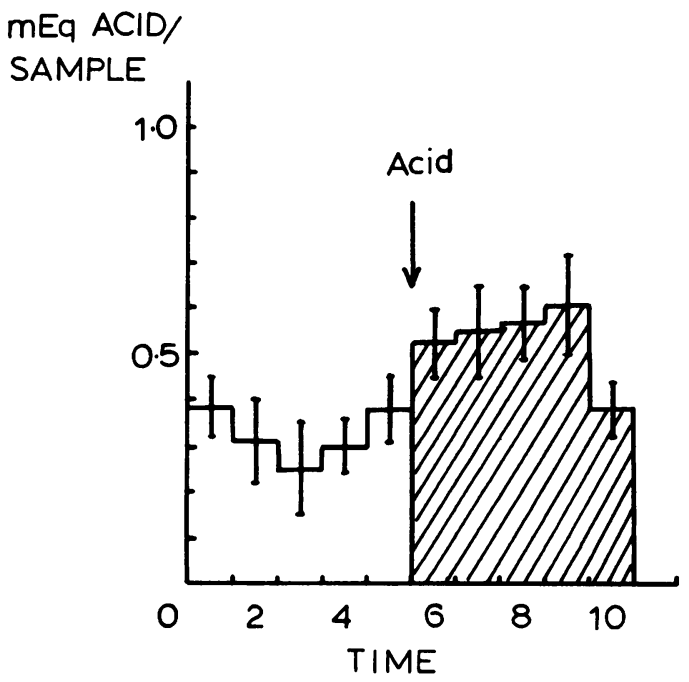

Fig. 2 Mean results in nine control subjects perfused with N/10 hydrochloric acid. Open columns denote basal secretion and shaded columns the output after perfusion; standard deviations are indicated. The same connotation is used in Figures 3 and 4.

the 30-minute period after instillation, both values expressed as milliequivalents per 10-minute sample. A half-hour period was chosen for comparison because the response was complete within this time in nearly all cases.

Tests were performed on 20 hiatus hernia patients before operation. There were 13 males and seven females in the group, and the mean age was 56 years. A sliding type of hernia was present in all, with free gastrooesophageal reflux on barium swallow. No other gastric or duodenal

ESTIMATIONS OF GASTRIC ASPIRATE

Three estimations were made: (1) volume of sample per 10-minute collection period; (2) $p \mathrm{H}$ and hydrogen ion concentration by titration to $p \mathrm{H} 7$ with $\mathrm{N} / 10$ sodium hydroxide; and (3) polyethylene glycol by a turbidimetric method (Malawer and Powell, 1967).

\section{Results}

\section{RECOVERY OF PEG}

Labelling the instilled acid with PEG enabled changes in endogenous acid secretion to be measured accurately. Nearly all the labelled acid appeared in the second and third 10-minute periods after instillation. Recovery was over $85 \%$ in all cases and in many tests a recovery of more than $95 \%$ was achieved.

\section{ACID OUTPUT}

Gastric secretion after oesophageal acidification was increased in all control subjects and in all except one of the hiatus hernia patients. The mean acid output in each group has been calculated from the individual results and is expressed in histogram form (Figs. 2-6).

\section{Control subjects}

A small increase in gastric secretion was observed in all nine controls (Fig. 2) after the instillation 
of acid into the oesophagus. Mean output in the basal period was $0.33 \mathrm{~m}$-equiv/10 $\mathrm{min}$ (SD \pm 0.15 ) increasing to $0.55 \mathrm{~m}$-equiv/10 $\mathrm{min}$ (SD \pm $0 \cdot 15)$ after perfusion.

In five subjects physiological $(0.9 \%)$ saline was instilled into the oesophagus without effect on basal gastric secretion. The response to acid in other groups cannot therefore be attributed to a volume effect or to oesophageal distension.

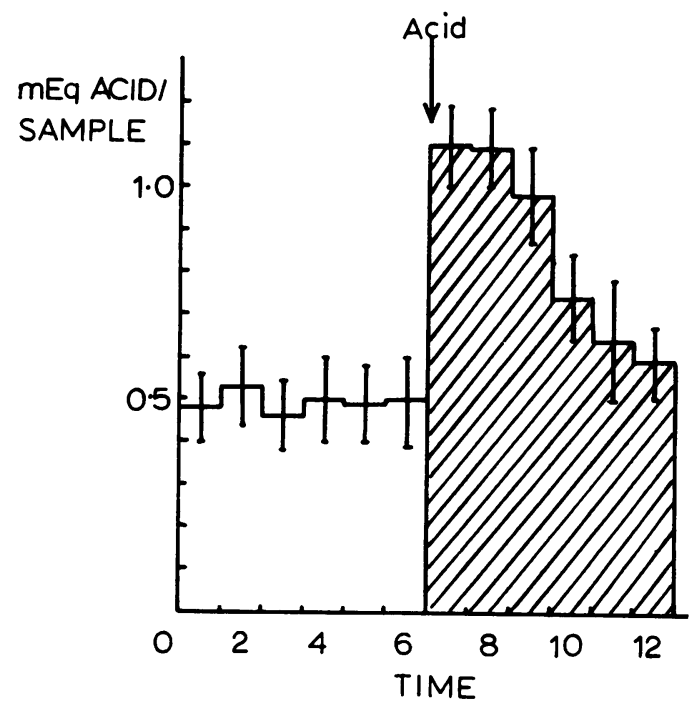

Fig. 3 Mean results in 20 preoperative hiatus hernia patients perfused with N/10 hydrochloric acid.

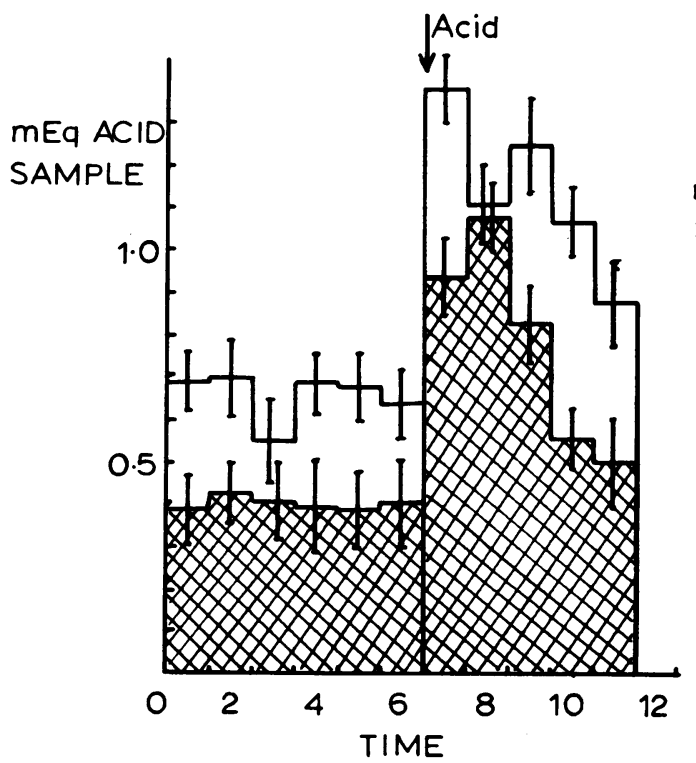

Fig. 5 Mean response to perfusion in preoperative hiatus hernia patients with and without oesophagitis. Open columns indicate acid output in the nonoesophagitis group and cross-hatched columns output in the oesophagitis group. The same connotation is used in Figure 6.
Hiatus hernia patients

Apart from one patient in whom mean acid output decreased from 0.37 m-equiv/10 min to $0.25 \mathrm{~m}$-equiv $/ 10 \mathrm{~min}$ after perfusion, all the hiatus hernia patients (Fig. 3) showed a marked increase in gastric secretion after the instillation of acid into the oesophagus. The basal rate for the group as a whole was $0.49 \mathrm{~m}$-equiv $/ 10 \mathrm{~min}$ $(\mathrm{SD} \pm 0 \cdot 17)$ and this increased to $1.05 \mathrm{~m}$-equiv/

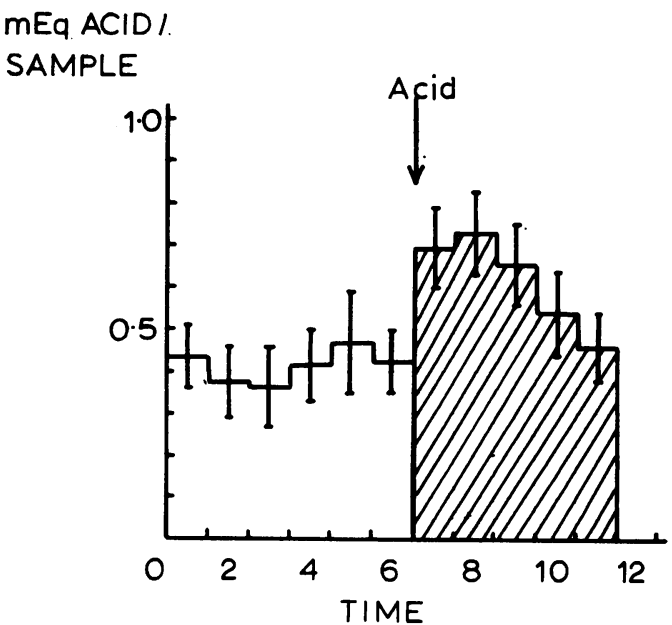

Fig. 4 Mean results in 12 postoperative hiatus hernia patients perfused with $N / 10$ hydrochloric acid.

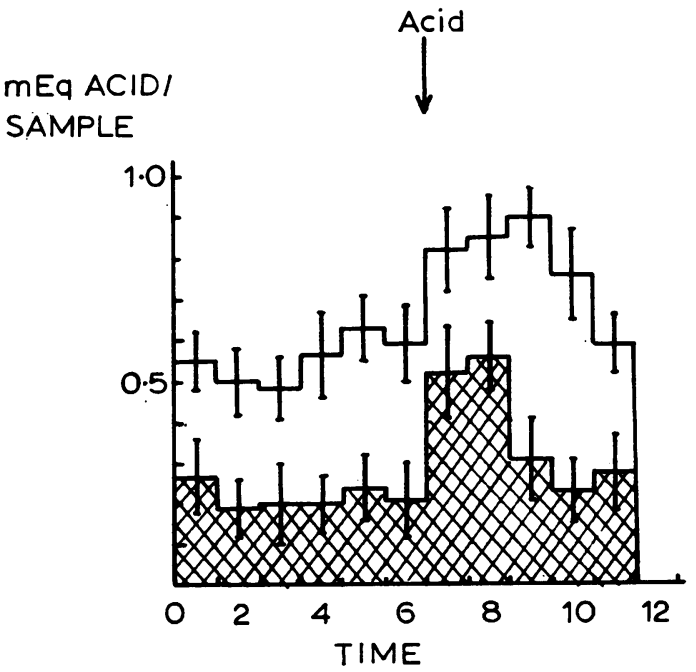

Fig. 6 Mean response to perfusion in oesophagitis and non-oesophagitis groups after hiatal repair. 
$10 \mathrm{~min}(\mathrm{SD} \pm 0 \cdot 18)$ after perfusion. As in the control group the response was immediate in onset and lasted for approximately 30 minutes.

\section{Hiatal repair}

The basal secretory rate and the response to perfusion were reduced in all patients after hiatal repair (Fig. 4). The mean acid output was 0.41 $\mathrm{m}$-equiv/10 $\mathrm{min}(\mathrm{SD} \pm 0.16)$ in the basal period and $0.69 \mathrm{~m}$-equiv/10 $\mathrm{min}(\mathrm{SD} \pm 0.17)$ after perfusion.

\section{Oesophagitis v non-oesophagitis}

Thirteen patients with oesophagitis and seven patients without inflammatory change were tested before operation. The response in the two groups is shown in Figure 5. Mean basal output in the patients without oesophagitis was 0.66 $\mathrm{m}$-equiv/10 $\mathrm{min}(\mathrm{SD} \pm 0.15)$ increasing to 1.25 m-equiv/10 min (SD $\pm 0 \cdot 17)$ after perfusion. In the oesophagitis group basal output was 0.40 $\mathrm{m}$-equiv/10 $\mathrm{min}(\mathrm{SD} \pm 0 \cdot 16)$ and perfusion output $0.95 \mathrm{~m}$-equiv/10 min (SD \pm 0.18 ); both of these values are lower than in the preceding group. The influence of hiatal repair on the response is shown in Figure 6. The basal secretory rate and the response to perfusion were reduced in both groups though this effect appeared more marked in patients with oesophagitis.

\section{ACID CONCENTRATION}

Gastric hydrogen ion concentration remained unchanged in all groups after the instillation of acid into the oesophagus. Changes in acid output were therefore due solely to alteration in the volume of the gastric juice.

\section{Discussion}

The results of this study confirm the observations of Giles et al (1968) that acid in the lower oesophagus stimulates gastric secretion. There was an increase in basal acid output in 40 out of 41 tests in control subjects and hiatus hernia patients, though the magnitude of the response was not the same in all groups. The response appears to be initiated in the oesophagus, and this claim is supported by three lines of evidence. First, the proximal site of the perfusion zone and the slow rate of perfusion permitted a long segment of oesophagus to be exposed to stimulation for a reasonable period of time. Secondly, increase in gastric secretion occurred within the first 10 minutes of perfusion and often indeed was maximal at that time, whereas perfused acid was not recovered from the stomach until the second or third 10-minute period. Thirdly, instillation of hydrochloric acid into the stomach is not accompanied by an increase in secretory rate (Chapman, Werther, and Janowitz, 1968). It may be concluded therefore that the response is initiated by acid at a level proximal to the stomach.

Oesophageal pain following acid infusion has been described by several authors (Bernstein and Baker, 1958; Bennett and Atkinson, 1966), and pain followed in nine out of 16 patients reported by Giles et al (1968). However, in the present study only one hiatus hernia patient experienced heartburn during perfusion despite the high incidence $(65 \%)$ of oesophagitis. This discrepancy is almost certainly due to the low rate and short duration of perfusion compared with that in the previous studies.

It is difficult to provide a satisfactory explanation for the increase in gastric secretion which follows acid perfusion of the oesophagus in hiatus hernia patients and controls. There appears to be an excessive response associated with an unreduced hernia which disappears after surgical correction. The presence of oesophagitis with subsequent alleviation by hiatal repair is a possible explanation but one which is not supported by the results, since the response to acid occurs in all patients and controls irrespective of the presence or absence of inflammatory change. Perhaps an oesophageal mucosa which is constantly subject to reflux has an increased sensitivity to acid; control of the reflux would be expected to reduce this sensitivity and thereby diminish the response to oesophageal perfusion.

The stimulatory pathway is unknown, though the absence of an oesophageal secretagogue favours a neural rather than a humoral mechanism. Aylwin (1953) observed an increase in salivary, oesophageal, and gastric secretion in patients with oesophagitis and attributed these findings to a vagal reflex. Investigation of patients after vagotomy may provide further information on this topic.

There is no evidence that oesophagitis is associated with excessive gastric stimulation. Inflammation, however, may exist in the lamina propria or submucosa or the oesophagus despite a normal surface epithelium at endoscopy (Palmer, 1955), and, to take this factor into consideration, oesophageal biopsies from all the cases in the study were examined and the patients regrouped according to histological rather than endoscopic evidence of oesophagitis. The results, however, do not differ from those outlined above and the same conclusions may be drawn.

It is possible that the development of oesophagitis is more closely related to the length of episodes of reflux rather than to an excessive gastric response occurring as an isolated event. Whenever gastric contents reflux into the oesophagus damage may be produced by direct action on the mucosa and indirectly by the mechanism described; the longer the oesophagus is exposed to acid in this way the more likely is the development of progressive inflammatory change. 
I should particularly like to thank $\mathrm{Mr}$ J. L. Collis for his constant help and encouragement during this study and for the privilege of testing his patients. I am also indebted to Dr Roy Cockel and Mr C. W. O. Windsor for many helpful suggestions and to Miss Sheila Nutter for excellent technical assistance.

\section{References}

Aylwin, J. A. (1953). The physiological basis of reflux oesophagitis in sliding hiatal diaphragmatic hernia. Thorax, 8, 38-45.

Bennett, J. R., and Atkinson, M. (1966). Oesophageal acidperfusion in the diagnosis of precordial pain. Lancet, 2 , $1150-1152$.
Bernstein, L. M., and Baker, L. A. (1958). A clinical test for esophagitis. Gastroenterology, 34, 760-781.

Chapman, M. A., Werther, J. L., and Janowitz, H. D. (1968). Response of the normal and pathological human gastric mucosa to an instilled acid load. Gastroenterology, 55, 344-353.

Collis, J. L. (1961). A review of surgical results in hiatus hernia. Thorax, 16, 114-119.

Collis, J. L. (1968). Surgical control of reflux in hiatus hernia. Amer. J. Surg., 115, 465-471.

Giles, G. R., Clark, C. G., and Buchan, R. (1968). Effect of oesophageal perfusion with acid on basal gastric secretion. Gut, 9, 52-56.

Malawer, S. J., and Powell, D. W. (1967). An improved turbidimetric analysis of polyethylene glycol utilizing an emulsifier. Gastroenterology, 53, 250-256.

Palmer, E. D. (1955). Subacute erosive ('peptic') esophagitis. Arch. Path., 59, 51-57.

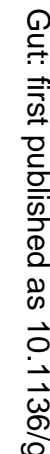

